\title{
Fullerene Bisadducts for Enhanced Open-Circuit Voltages and Efficiencies in Polymer Solar Cells**
}

\author{
By Mantijn Lenes, Gert-Jan A. H. Wetzelaer, Floris B. Kooistra, Sjoerd C. Veenstra, \\ Kees J. Hummelen, and Paul W. M. Blom*
}

With the recent rise in awareness of environmental issues, renewable-energy sources are being given more and more attention. Looking at photovoltaics, polymer:fullerene bulk heterojunction (BHJ) solar cells are considered to be a promising candidate for a large-area, flexible, and more importantly, low-cost renewable-energy source. ${ }^{[1]}$ Despite the fact that considerable progress has been made in this field of research, the relatively low power-conversion efficiencies, together with stability issues, are a drawback for commercialization of these devices. A significant part of the efforts made in this field has been the optimization of the fabrication of solar cells based on poly(3-hexylthiophene) (P3HT) as the donor and [6,6]-phenyl- $\mathrm{C}_{61}$-butyric acid methyl ester (PCBM) as the acceptor. ${ }^{[2-4]}$ In particular, the improvements made by thermal and solvent annealing have led to a situation where devices are made with external quantum efficiencies peaking at around $80 \%$ and internal quantum efficiencies surpassing $90 \%$, leading to power-conversion efficiencies of $\sim 4 \%{ }^{[5]}$ From the observed quantum efficiencies it is clear that there is not much room for improvement for this donor-acceptor combination.

When analyzing the electronic levels of the P3HT:PCBM system, a significant loss mechanism can be identified: due to the high exciton binding energy in conjugated polymers, excitons rather than free carriers are created upon light absorption. By blending in an electron acceptor, it becomes energetically favorable for the electron to make a transfer to the acceptor, thus breaking up the exciton. For electron

[*] Prof. P. W. M. Blom, M. Lenes, G. A. H. Wetzelaer, Dr. F. B. Kooistra, Prof. K. J. Hummelen

Molecular Electronics, Zernike Institute for Advanced Materials University of Groningen

Nijenborgh 4, 9747 AG, Groningen (The Netherlands)

M. Lenes

Dutch Polymer Institute

P.O. Box 902, 5600 AX, Eindhoven (The Netherlands)

Dr. F. B. Kooistra, Prof. K. J. Hummelen

Molecular Electronics, Stratingh Institute for Chemistry

University of Groningen

Nijenborgh 4, 9747 AG, Groningen (The Netherlands)

Dr. S. C. Veenstra

Energy Research Centre of the Netherlands (ECN)

P.O. Box 1, 1755 ZG Petten (The Netherlands)

[**] The work of M. Lenes forms part of the research program of the Dutch Polymer Institute (project \#524). The authors would like to thank W.J.H. Verhees at the ECN for his assistance with the calibrated efficiency measurements. transfer from donor to acceptor to occur, the lowest unoccupied molecular orbital (LUMO) of the donor needs to be 0.3 to $0.5 \mathrm{eV}$ higher than the LUMO of the acceptor. ${ }^{[6,7]}$ In the case of P3HT, however, this energy difference is much higher, namely $1.1 \mathrm{eV}$. This results in a less than optimal open-circuit voltage $V_{\text {oc }}$, since the open-circuit voltage is ultimately limited by the difference between the highest occupied molecular orbital (HOMO) of the donor and the LUMO of the acceptor. ${ }^{[8,9]}$ There are two ways to reduce this energy offset, either on the donor or on the acceptor side. Upon lowering the LUMO of the donor, and thus lowering the polymer bandgap, the absorption is shifted towards lower energy, whilst maintaining a constant open-circuit voltage. In this approach it is the photocurrent that is improved, mainly due to an enhanced overlap between the donor absorption and the solar spectrum. ${ }^{[10]}$ Making use of a recently developed device model for polymer:fullerene BHJ solar cells, ${ }^{[11]}$ it was calculated that a lowering of the LUMO of the donor ultimately leads to efficiencies of the order of $6.5 \% .^{[12]}$ This efficiency can further be enhanced by applying these lowbandgap polymers in tandem configurations. ${ }^{[13,14]}$ Raising the LUMO of the acceptor, on the other hand, will directly result in a higher open-circuit voltage without affecting the absorption of the cell. It has been shown that the second approach is theoretically more beneficial for a single-layer solar cell, and results in an estimated efficiency of $8.4 \%$ when the LUMO offset is reduced to $0.5 \mathrm{eV} \cdot{ }^{[12]}$ Until now, acceptors with a higher LUMO than that of PCBM, for instance polymer acceptors ${ }^{[15]}$ or alternative fullerenes, ${ }^{[16]}$ suffer from negative side effects, such as insufficient charge transport, inefficient charge-dissociation, or morphology problems.

Here we introduce bisPCBM, which is the bisadduct analogue of [60]PCBM, as a new fullerene-based n-type semiconductor material. BisPCBM is normally obtained as a by-product of the preparation of PCBM. ${ }^{[17]}$ The bisPCBM fraction was separated from the rest of the product mixture using standard column chromatography (silicagel, eluent: chloroform/toluene 1:1). The fraction was collected after removal of the monoadduct fraction (i.e., [60]PCBM) and collection of the bisadduct mixture was continued until liquid chromography mass spectrometry (LC-MS) analysis showed the appearance of the trisadducts. BisPCBM consists of a number of regioisomers. The general structure of these isomers (with the second addend at various positions on the fullerene cage) is depicted in Figure 1. BisPCBM has a substantially 


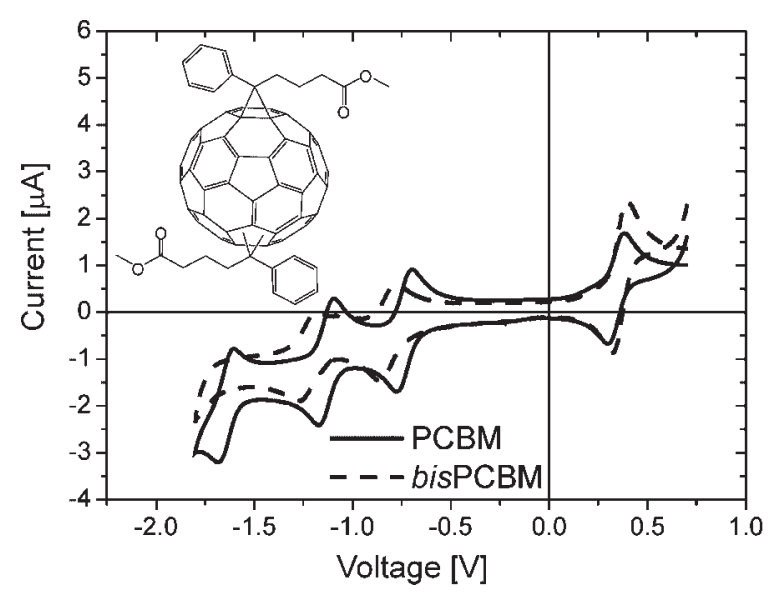

Figure 1. Cyclic voltammetry measurements performed on PCBM (solid line) and bisPCBM (dashed line). Experimental conditions: $V$ vs. ferrocene $(\mathrm{Fc}) / \mathrm{Fc}+; \mathrm{Bu}_{4} \mathrm{NPF}_{6}$ (tetrabutyl ammonium hexafluorophosphate, $0.1 \mathrm{M}$ ) was used as the supporting electrolyte, ODCB/acetonitrile $(4 / 1)$ as the solvent, and a scan rate of $10 \mathrm{mV} / \mathrm{s}$. The inset shows the generalized chemical structure of the bisPCBM regioisomers (i.e., the bottom-addend is attached in a cyclopropane manner at various $[6,6]$ positions, relative to the top one).

higher LUMO than PCBM, ${ }^{[18]}$ as can be seen by a cyclic voltammetry $(\mathrm{CV})$ comparison of bisPCBM and PCBM. An increase of the LUMO level of $\sim 100 \mathrm{meV}$ was found, raising the LUMO to $3.7 \mathrm{eV}$ below the vacuum level. Earlier studies, where "PCBM multi-adduct", a mixture of higher adducts (i.e., bisadducts, trisadducts, and traces of higher adducts) was used, did not result in improved power-conversion efficiencies. ${ }^{[19]}$ For proper device operation, a well-defined LUMO is required, which is not the case in a mixture of higher fullerene adducts. In this study, a pure isomeric mixture of bisadducts was used. The bisadduct isomer mixture consisted of a minimum of three isomers, as confirmed by LC-MS, using an analytical Buckyprep HPLC column with cyclohexane/toluene (1:1) as the eluent. In addition, ${ }^{1} \mathrm{H}$ NMR spectroscopy showed the presence of at least 17 methoxy resonance signals indicating that the bisadducts consisted of a much more complex mixture of isomers.

Layers of pristine bisPCBM were investigated to determine whether the additional functionalization of the fullerene and the fact that the material contained a mixture of isomers had any negative side effects on the charge-transport properties. The electron transport through the fullerene was measured by sandwiching a layer of bisPCBM between a layer of indium tin oxide (ITO) covered with $\sim 70 \mathrm{~nm}$ of poly(3,4-ethylenedioxythiophene):poly(styrene sulfonate) (PEDOT:PSS) and a samarium $(5 \mathrm{~nm}) /$ aluminum $(100 \mathrm{~nm})$ top electrode. Since the work function of PEDOT:PSS $(5.2 \mathrm{eV})$ is significantly lower than the HOMO of bisPCBM $(6.1 \mathrm{eV})$, hole injection into the fullerene can be neglected and thus only electrons flow under forward bias. Figure 2 shows the $J-V$ characteristics of a bisPCBM electron-only device with a thickness of $182 \mathrm{~nm}$, with the applied voltage corrected for the built-in voltage and series

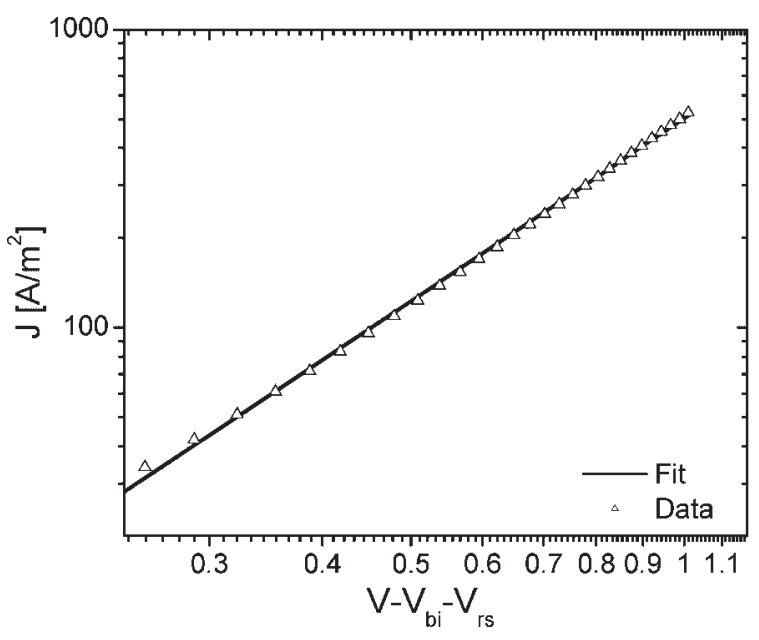

Figure 2. Current-density versus voltage, corrected for the built-in voltage and series resistance, of a bisPCBM electron-only device. Data (symbols) were fitted (solid line) using a space-charge limited current with a fielddependent mobility.

resistance of the contact. The transport through these singlecarrier devices is space-charge limited, resulting in a low-field electron mobility of $7 \times 10^{-8} \mathrm{~m}^{2} / \mathrm{Vs}$. Even though the measured electron mobility for bisPCBM is lower than the values reported for PCBM $\left(2 \times 10^{-7} \mathrm{~m}^{2} / \mathrm{Vs}\right)$, measured under the same conditions, ${ }^{[20]}$ the observed electron mobility is still expected to result in a balanced charge transport when combined with P3HT. Next, bisPCBM was used as an acceptor in a polymer:fullerene solar cell using the solvent-annealing technique. $^{[2]}$ P3HT and bisPCBM were dissolved in 1,2-dichlorobenzene (ODCB) by stirring the mixture for 2 days. The blend was spin-cast on top of the ITO layer, covered with PEDOT:PSS, and left to dry in a closed Petri dish for $48 \mathrm{~h}$. After the solvent annealing procedure, a short $(5 \mathrm{~min})$ thermal-annealing step was performed at $110^{\circ} \mathrm{C}$. To complete the preparation of the devices, a samarium $(5 \mathrm{~nm}) /$ aluminum $(100 \mathrm{~nm})$ top-contact was evaporated. Since bisPCBM has a lower electron mobility and higher molecular weight compared to PCBM, a different optimal composition of the blend was anticipated: optimization showed that a polymer/ fullerene weight ratio of $(1: 1.2)$ resulted in the highest efficiencies. The optimal active-layer thickness for P3HT:bisPCBM was found to be $\sim 250-300 \mathrm{~nm}$. After fabrication, the samples were evaluated and the best cells were shipped to the Energy Research Centre of the Netherlands (ECN) in a nitrogen-filled container to determine the device performance more accurately. As a reference, P3HT cells with PCBM in a 1:1 weight ratio were produced according to the same fabrication procedure. The optimal thickness of these cells was somewhat higher than for bisPCBM, that is, around $350 \mathrm{~nm}$.

Figure 3 shows the external quantum efficiency (EQE) for P3HT:bisPCBM and P3HT:PCBM solar cells. Even though 


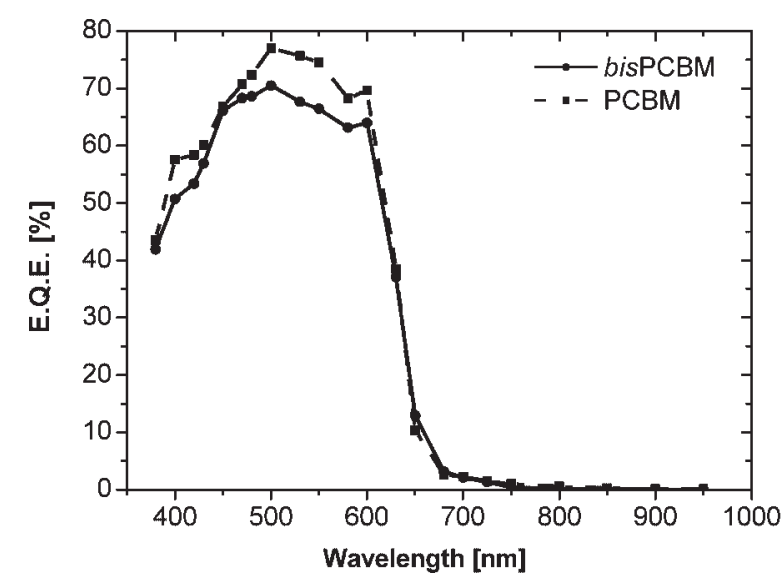

Figure 3. External quantum efficiencies of a $\mathrm{P} 3 \mathrm{HT}: \mathrm{PCBM}$ and $\mathrm{P} 3 \mathrm{HT}$ : bisPCBM solar cell.

similar in shape, PCBM devices showed slightly higher external quantum efficiencies, probably due to a thicker active layer. From the EQE measurements the short-circuit current density under air mass (AM) 1.5 conditions was estimated to be $96 \mathrm{~A} /$ $\mathrm{m}^{2}$ for P3HT:bisPCBM versus $104 \mathrm{~A} / \mathrm{m}^{2}$ for P3HT:PCBM. Figure 4 shows the $J-V$ characteristics of the cells, which were measured using a halogen lamp with a light output equivalent to an AM1.5 light source with an intensity of $1.16 \mathrm{~kW} / \mathrm{m}^{2}$. The open-circuit voltage of the P3HT:bisPCBM cell was $0.73 \mathrm{~V}$, $0.15 \mathrm{~V}$ higher than that of the P3HT:PCBM cell. As predicted by the EQE measurements, the short-circuit current is only slightly lower for P3HT:bisPCBM. Due to the enhanced $V_{\mathrm{oc}}$, bisPCBM was clearly the superior acceptor in combination with P3HT.

In order to obtain accurate values for the efficiencies, calibrated measurements were needed. To that end, the performance of our best cell was determined under simulated

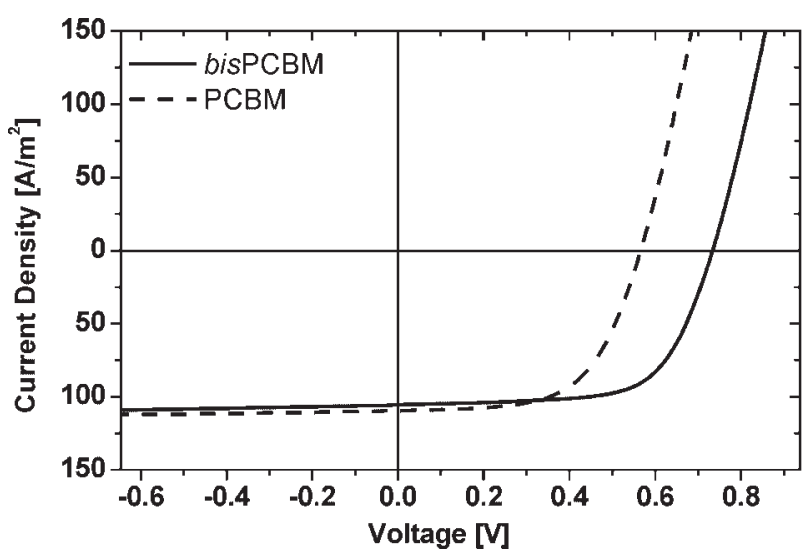

Figure 4. Current-density versus voltage curves of $\mathrm{P} 3 \mathrm{HT}$ : $\mathrm{PCBM}$ and $\mathrm{P} 3 \mathrm{HT}$ :bisPCBM solar cells under illumination of a halogen lamp with an intensity equivalent to 1.16 sun $\left(1 \mathrm{sun}=1000 \mathrm{~W} / \mathrm{m}^{2}\right)$.
AM1.5 illumination conditions (at an intensity of $1000 \mathrm{~W} / \mathrm{m}^{2}$ ) with a Wacom solar simulator (see Experimental). These externally verified measurements gave an open-circuit voltage of $0.724 \mathrm{~V}$, a fill factor of $68 \%$, and a short-circuit current of $91.4 \mathrm{~A} / \mathrm{m}^{2}$. The resulting power-conversion efficiency was $4.5 \%$ for a P3HT:bisPCBM solar cell with an active area of $0.16 \mathrm{~cm}^{2}$. Devices with larger active areas of $1 \mathrm{~cm}^{2}$ showed a small decrease in the fill factor, to $62 \%$, resulting in efficiencies of $4.1 \%$. The discrepancy between the calculated short-circuit current from the EQE measurements and the AM 1.5 current was probably due to the absence of bias illumination during the EQE measurement. The efficiency of $4.5 \%$ is about a factor of 1.2 larger as compared to the efficiencies of our best P3HT:PCBM cells of $3.8 \%$. This improvement is entirely due to the increase of the $V_{\mathrm{oc}}$. A similar improvement is also expected for other polymer:fullerene systems, for example low-bandgap cells, for which $5 \%$ efficiency has been claimed recently. ${ }^{[21]}$

We have presented a novel type of fullerene, bisPCBM, with a higher LUMO level compared to that of PCBM, in order to minimize the energy loss in the electron transfer from the donor to the acceptor material in bulk heterojunction solar cells. The additional functionalization of the fullerene cage in bisPCBM was shown to have little negative influence on the charge-carrier properties of the fullerene. As predicted, the higher LUMO resulted in a significantly enhanced open-circuit voltage when used in combination with $\mathrm{P} 3 \mathrm{HT}$, while maintaining a high short-circuit current and fill factor. An externally verified power-conversion efficiency of $4.5 \%$ was reported for a P3HT:bisPCBM solar cell. We showed that the bisadduct isomer mixture, free of monoadduct and higher adducts, can be used without further separation of the individual isomers, resulting in an enhanced cell performance compared to that of PCBM.

\section{Experimental Details}

All devices were prepared as follows: the prepatterned ITO-covered glass substrates were first cleaned using soapy water, acetone, demineralized water, isopropyl alcohol, and UV-ozone treatment. Subsequently, a layer of PEDOT:PSS (Bayer AG) was spin-coated under ambient conditions onto the cleaned substrates and the layer was dried by annealing the substrate. In the case of electron single-carrier devices, a layer of bisPCBM was spin-coated from chloroform in an $\mathrm{N}_{2}$ atmosphere glove-box. For the solar cells, a blend of P3HT:bisPCBM in a 1:1.2 weight ratio was spin-coated from ODCB, which was prepared two days in advance. The active layer was left to dry in a closed Petri dish for 48 hours. After solvent annealing, a short (5 min) thermal-annealing step was performed at $110^{\circ} \mathrm{C}$. All devices were completed by thermal evaporation of a $5 \mathrm{~nm}$ samarium $/ 100 \mathrm{~nm}$ aluminum top-contact under vacuum $\left(5 \times 10^{-6} \mathrm{mbar}, 1 \mathrm{ppm} \mathrm{O}_{2}\right.$, and $\left.<1 \mathrm{ppm} \mathrm{H}_{2} \mathrm{O}\right)$. The current density versus voltage curves were measured in a $\mathrm{N}_{2}$ atmosphere at room temperature using a computer-controlled Keithley 2400 Source Meter. $J-V$ characteristics of the solar cells were determined at the ECN using a white-light halogen lamp with a light output equivalent to an AM1.5 light source with an intensity of $1.16 \mathrm{~kW} / \mathrm{m}^{2}$. For EQE measurements, the same halogen lamp was used in combination with a series of interference filters. For standard test condition (STC) measurements, a 
WXS-300S-50 solar simulator (WACOM Electric Co.) was used. The mismatch factor of 0.992 was calculated using a recent spectrum of the simulator lamp and the spectral responses of the used filtered $\mathrm{Si}$ reference cell (calibrated at the Fraunhofer ISE, Freiburg) and the polymer:fullerene cell, respectively.

Received: September 26, 2007

Revised: November 14, 2007

Published online:

[1] C. J. Brabec, N. S. Sariciftci, J. C. Hummelen, Adv. Funct. Mater. 2001, $11,15$.

[2] G. Li, V. Shrotriya, J. Huang, Y. Yao, T. Moriarty, K. Emery, Y. Yang, Nat. Mater. 2005, 4, 864.

[3] F. Padinger, R. S. Rittberger, N. S. Sariciftci, Adv. Funct. Mater. 2003, 13,85 .

[4] W. Ma, C. Yang, X. Gong, K. Lee, A. J. Heeger, Adv. Funct. Mater. 2005, 15, 1617 .

[5] G. Dennler, K. Forberich, M. C. Scharber, C. J. Brabec, I. Tomis, K. Hingerl, T. Fromherz, J. Appl. Phys. 2007, 102, 054516.

[6] J. M. Halls, J. Cornill, D. A. dos Santos, R. Silbey, D.-H. Hwang, A. B. Holmes, J. L. Brédas, R. H. Friend, Phys. Rev. B 1999, 60, 5721.

[7] C. J. Brabec, C. Winder, N. S. Sariciftci, J. C. Hummelen, A. Dhanabalan, P. A. van Hal, R. A. J. Janssen, Adv. Funct. Mater. 2002, 12, 709.

[8] L. J. A. Koster, V. D. Mihailetchi, R. Ramaker, P. W. M. Blom, Appl. Phys. Lett. 2005, 86, 123509.

[9] C. J. Brabec, A. Cravino, D. Meissner, N. S. Sariciftci, T. Fromherz, M. T. Rispens, L. Sanchez, J. C. Hummelen, Adv. Funct. Mater. 2001, 11,374 .
[10] D. Mühlbacher, M. Scharber, M. Morana, Z. Zhu, D. Waller, R. Gaudiana, C. Brabec, Adv. Mater. 2006, 18, 2884.

[11] L. J. A. Koster, E. C. P. Smits, V. D. Mihailetchi, P. W. M. Blom, Phys. $\operatorname{Rev} B$ 2005, 72, 085205.

[12] L. J. A. Koster, V. D. Mihailetchi, P. W. M. Blom, Appl. Phys. Lett. 2006, $88,093511$.

[13] A. Hadipour, B. de Boer, J. Wildeman, F. B. Kooistra, J. C. Hummelen, M. G. R. Turbiez, M. M. Wienk, R. A. J. Janssen, P. W. M. Blom, Adv. Funct. Mater. 2006, 16, 1897.

[14] J. Y. Kim, K. Lee, N. E. Coates, D. Moses, T. Nguyen, M. Dante, A. J. Heeger, Science 2007, 317, 222.

[15] C. R. McNeill, A. Abrusci, J. Zaumseil, R. Wilson, M. J. McKiernan, J. H. Burroughes, J. J. M. Halls, N. C. Greenham, R. H. Friend, Appl. Phys. Lett. 2007, 90, 193506.

[16] F. B. Kooistra, J. Knol, F. Kastenberg, L. M. Popescu, W. J. H. Verhees, J. M. Kroon, J. C. Hummelen, Org. Lett. 2007, 9, 551.

[17] J. C. Hummelen, B. W. Knight, F. Lepec, F. Wudl, J. Yao, C. L. Wilkins, J. Org. Chem. 1995, 60, 532.

[18] F. Diederich, R. Kessinger, Acc. Chem. Res. 1999, 32, 537.

[19] a) F. Padinger, C. J. Brabec, T. Fromherz, J. C. Hummelen, N. S. Sariciftci, Optoelectron. Rev. 2000, 8, 280. b) D. Gebeyehu, C. J. Brabec, F. Padinger, T. Fromherz, J. C. Hummelen, D. Badt, H. Schindler, N. S. Sariciftci, Synth. Met. 2001, 118, 1. c) D. Gebeyehu, F. Padinger, T. Fromherz, J. C. Hummelen, N. S. Sariciftci, Bull. Chem. Soc. Ethiop. 2000, 1, 57. d) D. Gebeyehu, F. Padinger, C. J. Brabec, T. Fromherz, J. C. Hummelen, N. S. Sariciftci, Int. J. Photoenergy 1999, 1, 95. e) T. Fromherz, F. Padinger, D. Gebeyehu, C. J. Brabec, J. C. Hummelen, Sol. Energy Mater. Sol. Cells 2000, 63, 61.

[20] V. D. Mihailetchi, J. K. J. van Duren, P. W. M. Blom, J. C. Hummelen, R. A. J. Janssen, J. M. Kroon, M. T. Rispens, W. J. H. Verhees, M. M. Wienk, Adv. Funct. Mater. 2003, 13, 43.

[21] J. Peet, J. Y. Kim, N. E. Coates, W. L. Ma, D. Moses, A. J. Heeger, G. C. Bazan, Nat. Mater. 2007, 9, 497. 